\title{
Pathogenic Mechanisms of Bacterial Enteropathogens
}

\author{
Toshio Mrwatani, Mitsuo Kohda and Takeshi Honda \\ Research Institute for Microbial Diseases, Osaka University, Yamadaoka, Suita, Osaka, 565
}

(Received for publication, December 18, 1987)

Key words: Colonization; enterotoxigenic Escherichia coli; diarrhea; toxin

Two important steps are involved in the pathogenesis of bacterial enteric pathogens. All the enteric pathogens, which enter the gastrointestinal tract through the mouth with food or water, colonize a certain part of the intestine. This important step is called colonization (4,9). For example, Vibrio cholerae and Vibrio parahaemolyticus colonize the mucosa of the upper jejunum, whereas Shigella colonizes the ileocaecum and colon. This event (colonization) is mediated by the production of specific surface antigens called "colonization factors" and specific receptors for the factors. The reason for the differences between the symptoms produced by $V$. cholerae $\mathrm{O} 1$ and $V$. parahaemolyticus, both of which colonize a similar region of the small intestine, is that they produce different toxins. Thus the second important step in the pathogenesis of bacterial enteric pathogens is the production of toxins and/or invasion.

\section{COLONIZATION FACTORS (ADHESINS)}

The most extensive studies on colonization factors (adhesins) of bacterial enteropathogens have been on those of enterotoxigenic Escherichia coli (ETEC). Several colonization factors have been found in ETEC strains isolated from human patients and domestic animals (Table 1). Colonization factors (CFA) for ETEC are usually identified morphologically as pili on the bacterial surface, as shown in Fig. 1, and with a few exceptions, the presence of CFAs is associated with mannose-resistant hemagglutination and high bacterial surface hydrophobicity. Although heterogeneity of CFA/I has not been demonstrated, heterogeneities of CFA/II and P8775 have been observed, as summarized in Table 1 .

\section{GROUPING OF ENTEROPATHOGENS BY THEIR MECHANISMS OF PATHOGENICITY}

As mentioned above, colonization, that is attachment of the bacteria to the mucosa, is the first step in pathogenesis. Thereafter, the colonized organisms attack 
Table 1. Characteristics of colonization factor of ETEC of human origin

\begin{tabular}{|c|c|c|c|c|}
\hline $\begin{array}{l}\text { Colonization } \\
\text { factor }\end{array}$ & Morphology & $\begin{array}{l}\text { Molecular weight } \\
\text { of subunit }\end{array}$ & $\begin{array}{c}\text { Gene } \\
\text { location }\end{array}$ & $\begin{array}{l}\text { Erythrocytes } \\
\text { agglutinated }\end{array}$ \\
\hline CFA/I & $\operatorname{Rigid}(\phi 7 \mathrm{~nm})$ & $\begin{array}{l}15,058(12,000- \\
23,800)\end{array}$ & Plasmid & Human, Bovine, Chicken \\
\hline \multicolumn{5}{|l|}{ CFA/II } \\
\hline CS1 & Rigid $(\phi 7 \mathrm{~nm})$ & $16,800(16,300)$ & Plasmid & Human, Bovine, Chicken \\
\hline CS2 & Rigid $(\phi 7 \mathrm{~nm})$ & 15,300 & Plasmid & Bovine, Chicken \\
\hline CS3 & Flexible $(\phi 2 \mathrm{~nm})$ & $\begin{array}{l}14,500+15,500 \\
(14,800)\end{array}$ & Plasmid & Bovine \\
\hline CFA/III & Rigid & 16,000 & Plasmid? & Human, Bovine, Chicken \\
\hline $\mathrm{HP} / \mathrm{III}$ & Rigid & 18,000 & Plasmid & - \\
\hline \multicolumn{5}{|l|}{ PCF8775 } \\
\hline CS4 & Rigid $(\phi 7 \mathrm{~nm})$ & ? & Plasmid? & Human, Bovine \\
\hline CS5 & $\operatorname{Rigid}(\phi 7 \mathrm{~nm})$ & ? & Plasmid? & $\begin{array}{l}\text { Human, Bovine, Guinea } \\
\text { Pig }\end{array}$ \\
\hline CS6 & - & ? & Plasmid? & - \\
\hline PCFO157: H4 & Rigid $(\phi 8 \mathrm{~nm})$ & 19,000 & Plasmid & - \\
\hline O148: H28Pili & Flexible $(\phi 3 \mathrm{~nm})$ & ? & ? & - \\
\hline
\end{tabular}

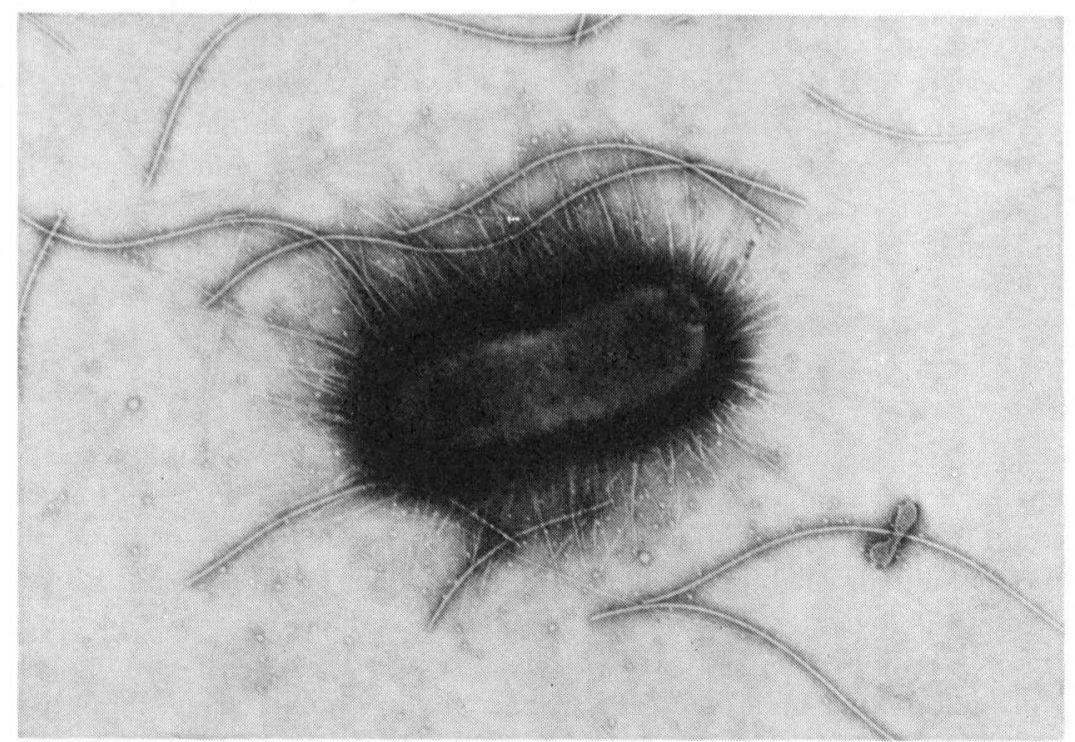

Fig. 1. Electron microscopic appearance of ETEC possessing fimbrial colonization factor.

human cells or organs by producing toxins or invading the cells and/or tissues. Thus, enteropathogens can be divided into two groups: a toxin type and an invasive type. 


\section{(I) Pathogens of the Enteroinvasive Type}

Shigella, enteroinvasive E. coli (EIEC), Salmonella, Campylobacter jejuni, C. coli and Yersinia enterocolitica (3) are of this type. Most of these pathogens invade epithelial cells of the intestine, but Salmonella invades through intercellular junctions of epithelial cells. But it is now becoming evident that some of these enteroinvasive pathogens classified as the invasive type do in fact produce toxins. For instance, $S$. dysenteriae produces Shiga toxin (11) and $Y$. enterocolitica produces ST-like enterotoxin (12).

\section{(II) Pathogens of the Toxin-producing Type}

As listed in Table 2, many enteropathogens produce toxins, including enterotoxins and lethal toxins, that are responsible for their pathogenesis.

Enterotoxins can be divided into three groups: those with a morphologically cytotonic effect, a cytotoxic effect or no effect on cultured Chinese hamster ovary (CHO) cells and Y1 adrenal tumor cells, as classified in Table 3. Cholera enterotoxin (CT) and heat-labile enterotoxin (LT) of ETEC are examples of cytotonic enterotoxins. Shiga toxin (11) and Clostridium difficile cytotoxin are examples of cytotoxic enterotoxins, and staphylococcal enterotoxin and heat-stable enterotoxin

Table 2. Grouping of enteropathogens

\begin{tabular}{lll}
\hline I. Enteroinvasive type & II. & Toxin-producing type \\
1) Shigella dysenteriae & 1) Staphylococcus aureus \\
2) Enteroinvasive E. coli & 2) Clostridium botulinum \\
3) Yersinia enterocolitica & 3) Vibrio cholerae O1 \\
4) Campylobacter jejuni/coli & 4) V. cholerae non-O1 (NAG vibrio) \\
5) Salmonella spp. & 5) Enterotoxigenic E. coli (ETEC) \\
& 6) Vibrio parahaemolyticus \\
& 7) Clostridium difficile \\
& 8) Clostidium perfringens \\
& 9) Aeromonas hydrophila/sobria \\
& 10) Bacillus cereus \\
& 11) Plesiomonas shigelloides \\
\hline
\end{tabular}

Table 3. Classification of diarrhogenic toxins

I. Cytotonic toxin

Cholera toxin (V. cholerae $\mathrm{Ol})$

Heat-labile enterotoxin (LT) (ETEC)

CT/LT family: Salmonella typhimurium, Campylobacter jejuni, Klebsiella

Other: Clostridium difficile

pneumoniae, Enterobacter

II. Cytotoxic toxin

Shiga toxin (Shigella dysenteriae)

Shiga-like toxin (Enterohemorrhagic E. coli)

C. perfringens enterotoxin

III. Toxins causing no morphological change

Heat-stable enterotoxin (ST) (ETEC)

$S$. aureus enterotoxin 
(ST) of ETEC are examples of the third group.

Lethal toxins can be divided into two types: One type has a rapid action. This type includes thermostable direct hemolysin (TDH) of V. parahaemolyticus and enterotoxin of Clostridium perfringens type A, which at low doses can kill animals within seconds or minutes. The other type has a delayed lethal action. This type includes Shiga toxin and botulinum toxin, which kill animals only after several hours.

\section{CHARACTERIZATION OF PROTEIN TOXINS PRODUCED BY ENTEROPATHOGENS}

\section{Enterotoxins}

Enterotoxins, diarrhogenic toxins, should induce positive reactions in (a) the
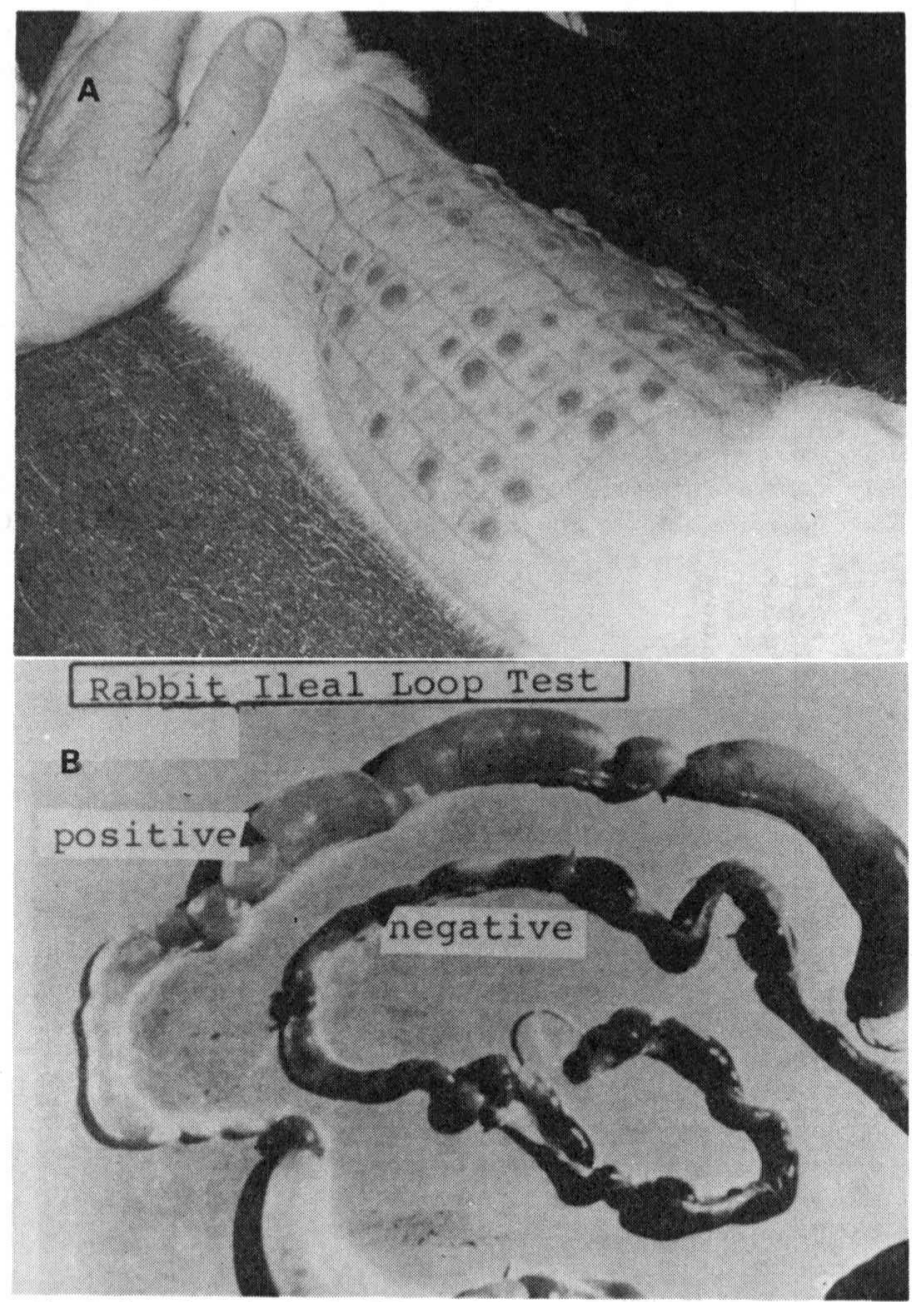

Fig. 2. Examples of results in the PF test (A) and rabbit ileal loop test (B). 


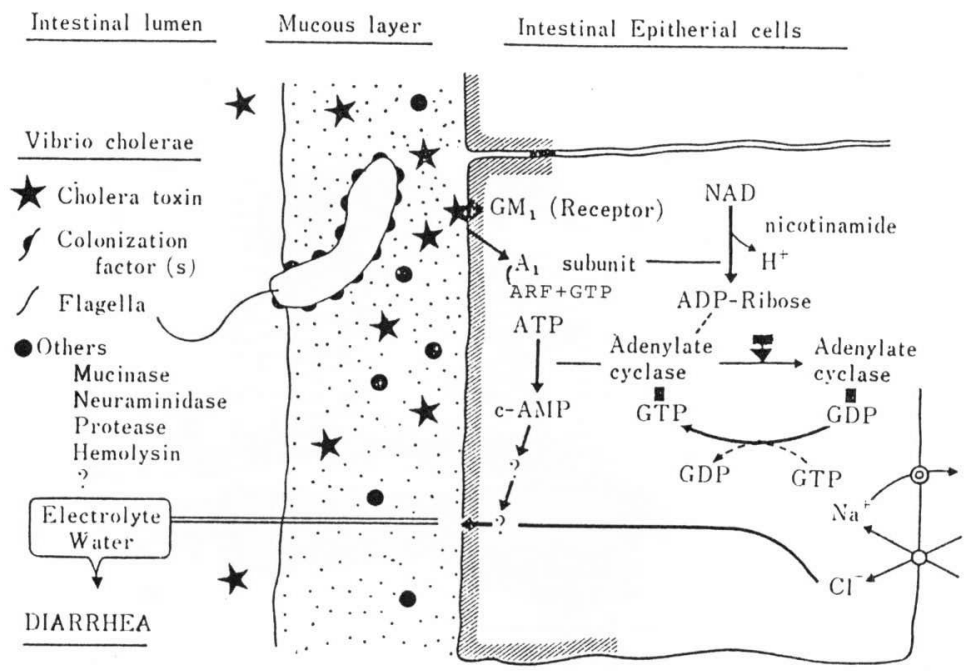

Fig. 3. Mechanism of induction of diarrhea by $V$. cholerae (CT produced by colonized $V$. cholerae binds to $\mathrm{G}_{\mathrm{M} 1}$ ganglioside receptor and the internalized Al subunit acts as an enzyme).

ileal loop test, and (b) the skin permeability (PF) test. Examples of results in these tests are shown in Fig. 2.

(i) Enterotoxin of the CT and LT groups. These two typical cytotonic enterotoxins possess biologically, immunologically and physicochemically similar characters $(9,13)$. Similar toxins have been found in cultures of Campylobacter jejuni, Salmonella and Klebsiella. $\mathrm{CT} / \mathrm{LT}$ are composed of A and B subunits. The A subunit, which consists of Al and A2 fragments, is enzymatically active, while the B subunit binds the toxin to its ganglioside receptor.

Figure 3 illustrates the mechanism of the effects of CT/LT: CT binds to ganglioside GM1 receptor through its B subunit, and the Al fragment causes enzymatic ADP-ribosylation of the GTP-binding regulatory component $\left(\mathrm{G}_{\mathrm{s} \alpha}\right)$ of adenylate cyclase. CT/LT thus inhibits the GTPase turn-off reaction, resulting in activation of adenylate cyclase in the cell membrane. The steps after adenylate cyclase activation with consequent accumulation of intracellular cyclic AMP are still unknown.

CT/LT activity can be measured by CHO cell assay (Fig. 4). This assay depends on the fact that $\mathrm{CHO}$ cells change from a round to a spindle-shape when they accumulate cAMP. Several immunological methods including the Biken test (a modified Elek test) (5) and ELISA (6) have also been developed for detecting CT/LT.

(ii) Various STs. ST was found initially in $\operatorname{ETEC}(9,16)$, and subsequently in $Y$. enterocolitica (12), $V$. mimicus and $V$. cholerae non-O1 (16). Two distinct STs, STI (STa) and STII (STb) (8), are recognized in ETEC. STI is active in suckling mice, whereas STII induces fluid accumulation in the intestine of piglets only. 


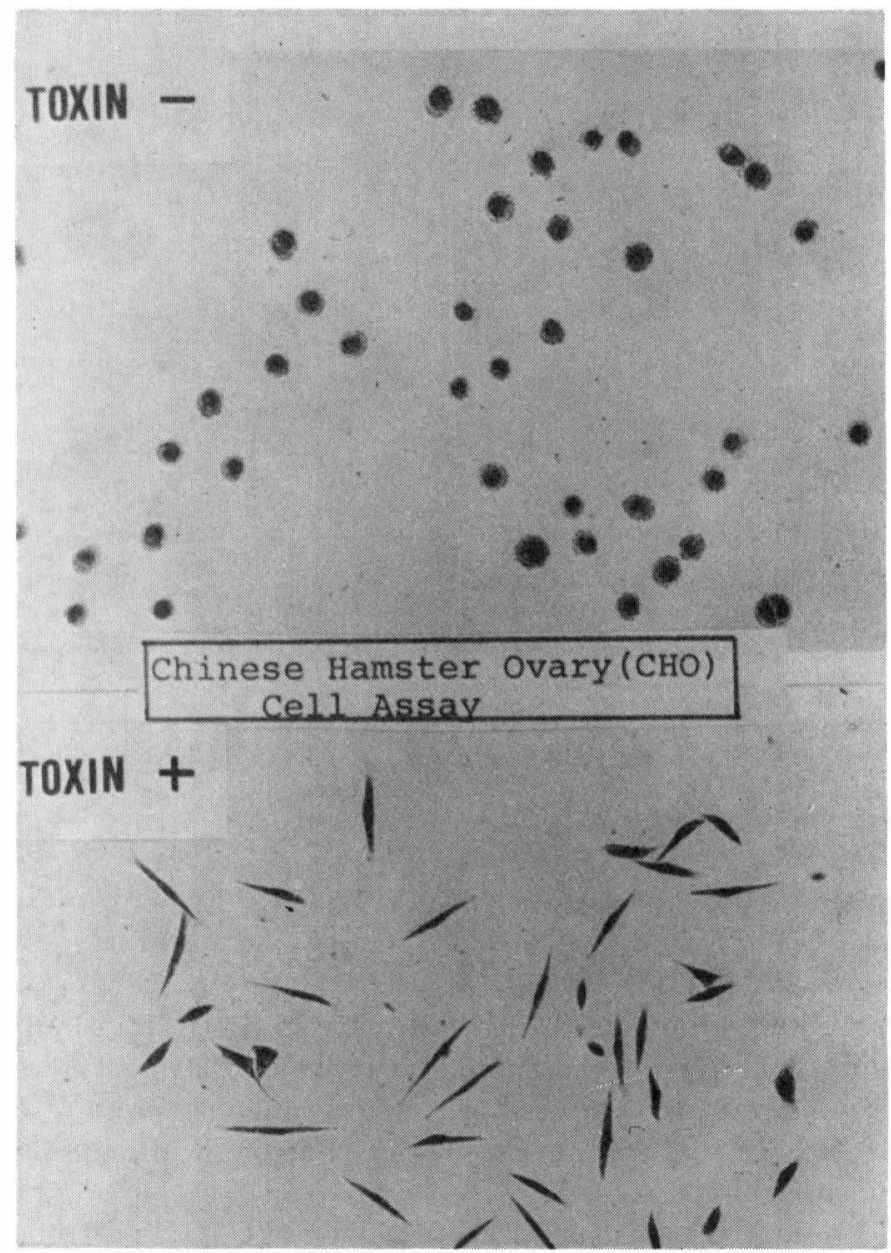

Fig. 4. Morphological change of $\mathrm{CHO}$ cells induced by CT.

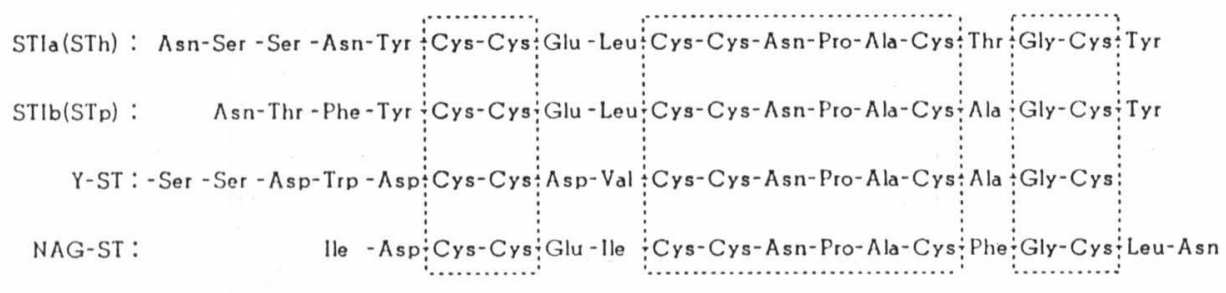

Fig. 5. Amino acid sequences of various STs. STh and STp are from ETEC. Y-ST is from $Y$. enterocolitica. NAG-ST and VM-ST are from $V$. cholerae non-Ol and V. mimicus, respectively. Common regions are boxed. 
There are two subtypes of STI: STp, found in strains isolated from humans as well as animals, and STh, found in strains isolated from humans. Figure 5 shows the amino acid sequences so far known of various STs. These STs have very similar structures. In particular, the positions of the six half-cystines are identical and thus the 13 amino acids from the first to the last Cys seem to be important for expression of biological activity.

ST causes rapid activation of particulate guanylate cyclase in the brush border membrane, and there may be a receptor for ST (7). But it is unknown how elevation of cyclic GMP due to activation of guanylate cyclase is coupled to secretion.

ST activity can be detected by suckling mouse assay (Fig. 6). The activity is expressed as the ratio of the weight of the total intestine to the weight of the rest of the body.

(iii) Staphylococcal enterotoxin. After its absorption from the intestine, this toxin is thought to induce nausea and vomiting by stimulating the cerebral center for nausea/vomiting through autonomic nerves (vagus nerve). The toxin also inhibits intestinal movement and water absorption and stimulates intestinal secretion, thus causing diarrhea. The effect of the diarrhogenic activity of this toxin has yet to be elucidated (2).

Staphylococcal food poisoning is caused by the ingestion of food containing preformed toxins. These toxins vary in molecular weight from ca. 28,000 to 35,000. Some strains of staphylococci produce several antigenically distinct toxins (A, B, $\left.\mathrm{C}_{1}, \mathrm{C}_{2}, \mathrm{D}, \mathrm{E}\right)$ which cause food poisoning in humans (2). The most common clinical manifestations of staphylococcal food poisoning are diarrhea and emesis.

\section{Lethal Toxins}

(i) Thermostable direct hemolysin. Thermostable direct hemolysin (Vp-TDH)

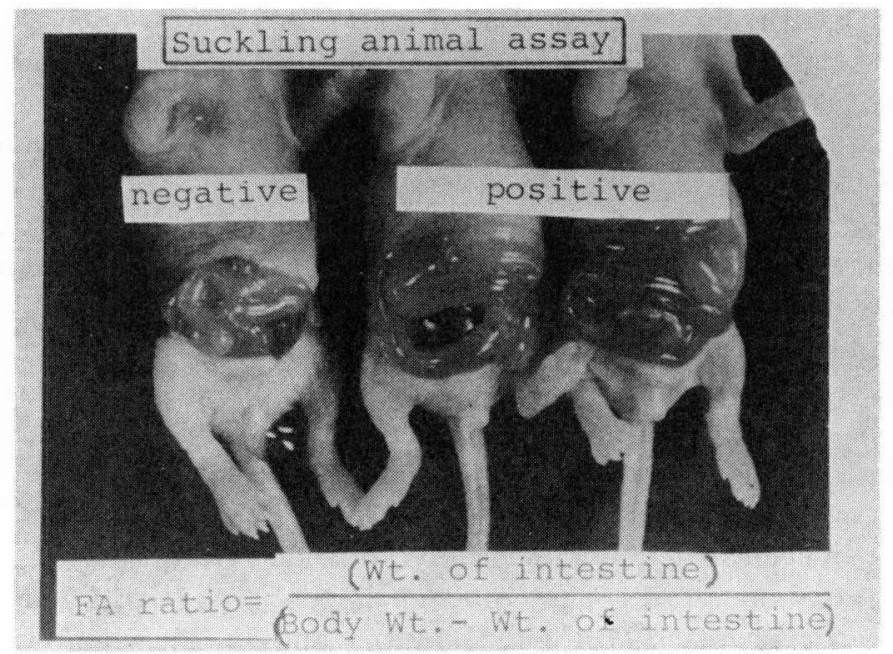

Fig. 6. Example of results in the suckling mouse assay. 


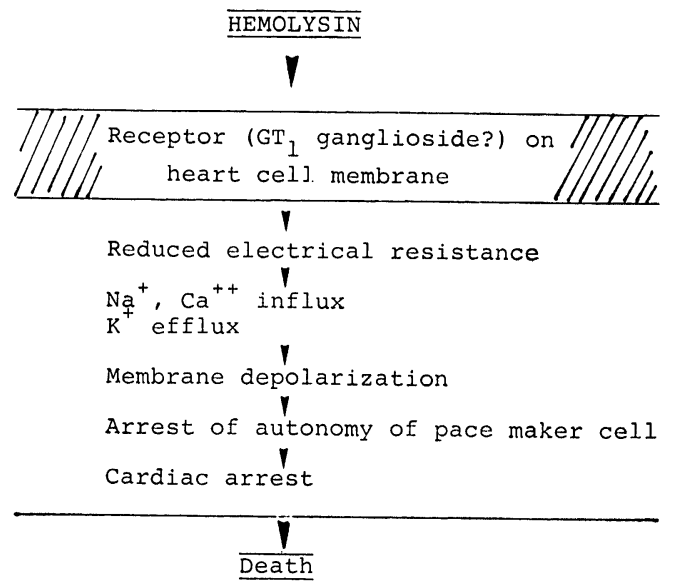

Fig. 7. Proposed mechanism of the lethal toxicity of Vp-TDH.

of $V$. parahaemolyticus is a typical example of a lethal toxin with rapid effect $(10)$. $\mathrm{Vp}-\mathrm{TDH}$ is a protein toxin that is responsible for the Kanagawa phenomenon. It has a molecular weight of $c a .40,000$ and consists of 2 identical subunits of $c a .21,000$ daltons. Vp-TDH has the following biological activities: (a) hemolytic activity on erythrocytes of various animals (but not those of horse), (b) cytotoxicity against various cultured mammalian cells, (c) rapid lethal toxicity to small experimental animals and probably (d) enteropathogenicity.

$\mathrm{Vp}-\mathrm{TDH}$ has a particularly strong and rapid lethal action in mice and rats. Intravenous injection of $5 \mu \mathrm{g}$ of $\mathrm{Vp}-\mathrm{TDH}$ kills mice in less than $1 \mathrm{~min}$. It has a cardiotoxic effect, as shown by analyses of electrocardiographic changes of rats after its injection, electrophysiological studies on rabbit heart muscle in a perfusion system, and studies on the effect of $\mathrm{Vp}-\mathrm{TDH}$ on the beating of mouse myocardial cells in vitro. We have proposed the mechanism for the lethal cardiotoxicity of $\mathrm{Vp}$ TDH shown in Fig. 7. Similar hemolysins to Vp-TDH were also found in cultures of $V$. cholerae non-01, $V$. mimicus and $V$. hollisae (15).

(ii) Shiga toxin. This protein toxin has an $\mathrm{AB}$ type structure. $\mathrm{A}$ is the active subunit with a molecular weight of 32,000 , which is composed of fragments $\mathrm{Al}$ and A2. Al has enzymatic activity to inhibit protein synthesis by affecting the $60 \mathrm{~S}$ ribosomal subunit of mammalian ribosomes. The B subunit binds toxin to the membrane receptor (probably a glycoprotein containing $\beta 1-4$ linked $N$-acetyl-Dglucosamine) and help the internalization of the A subunit into the cells. The same molecule shows cytotoxic, neurotoxic and enterotoxic activities. The role of the toxin in shigellosis is still unclear.

A toxin biologically, immunologically and structurally similar to Shiga toxin was demonstrated in cultures of enterohemorrhagic E. coli (EHEC) and some strains of enteropathogenic $E$. coli (EPEC), $V$. cholerae and $V$. parahaemolyticus and named Vero toxin (VT-1) or Shiga-like toxin (SLT) because it has cytotoxic effects on Vero 
cells similar to Shiga toxin (11). Another toxin that is biologically similar to, but immunologically different from Shiga toxin was demonstrated in cultures of EHEC and named VT-II.

(iii) Botulinum toxin. Clostridium botulinum produces at least eight distinct neurotoxins named $\mathrm{A}, \mathrm{B}, \mathrm{C}_{1}, \mathrm{C}_{2}, \mathrm{D}, \mathrm{E}, \mathrm{F}$ and $\mathrm{G}$ (14). They are immunologically different from each other, but the structures and activities of all of them except $\mathrm{C}_{2}$ are essentially similar. The toxins consist of two distinct components, a nontoxic component (Mt. ca. 500,000) and a toxic component (Mt. ca. 150,000). The complex of these components is referred to as progenitor toxin. The toxic component consists of two non-identical fragments: a heavy chain (Mt. ca. 100,000) and a light chain (Mt. ca. 50,000). The $\mathrm{C}$ terminal region of the heavy chain is thought to be the receptor binding portion. It is believed that, like tetanus toxin, botulinum toxin acts presynaptically to block neurotransmitter (acetyl choline) release. The exceptional botulinum toxin, $\mathrm{C}_{2}$, is not a neurotoxin but an enterotoxin. $\mathrm{C}_{2}$ toxin consists of 2 independent proteins, $\mathrm{C}_{2}-1$ and $\mathrm{C}_{2}-2$, that act synergistically. $\mathrm{C}_{2}$ toxin was recently found to be an enzyme that catalizes ADP-ribosylation (1).

As described in this report, it is now evident that many pathogens, including organisms of the invasive type, produce various kinds of toxins. Thus more studies on toxins are required than were originally anticipated. It is also important to obtain more information on colonization.

Acknowledgements. This work was partly supported by a Grant-in-Aid for Scientific Research from the Ministry of Education, Science and Culture of Japan.

\section{REFERENCES}

(1) Aktories, K., M. Bärmann, I. Ohishi, S. Tsuyama, K. H. Jakobs, and E. Habermann. 1986. Botulinum $\mathrm{C}_{2}$ toxin ADP-ribosylates actin. Nature 322: 390-392.

(2) Bergdoll, M.S. 1979. Staphylococcal intoxications, p. 443-494. In H.R. Riemann and F.L. Bryan (eds.), Foodborne infections and intoxications, Academic Press, Inc., New York.

(3) Cornelis, G., Y. Laroche, G. Balligand, M.-P. Sory, and G. Wauters. 1987. Yersinia enterocolitica, a primary model for bacterial invasiveness. Rev. Infect. Dis. 9: 64-87.

(4) Gaastra, W., and F.K. DeGraaf. 1982. Host-specific fimbrial adhesions of noninvasive enterotoxigenic Escherichia coli. Microbiol. Rev. 46: 129-161.

(5) Honda, T., M. Arita, Y. Takeda, and T. Miwatani. 1982. Further evaluation of the Biken test (modified Elek test) for detection of enterotoxigenic Escherichia coli producing heat-labile enterotoxin and application of the test to sampling of heat-stable enterotoxin. J. Clin. Microbiol. 16: 60-62.

(6) Honda, T., M. Sato, and T. Miwatani. 1984. Differential detection of cholera enterotoxin and Escherichia coli heat-labile enterotoxin by enzyme-linked immunosorbent assays with antibodies specific to the two toxins. J. Clin. Microbiol. 20: 664-667.

(7) Kuno, T., Y. Kamisaki, S.A. Waldman, J. Gariepy, G. Schoolnik, and F. Murad. 1986. Characterization of the receptor for heat-stable enterotoxin from Escherichia coli in rat intestine. J. Biol. Chem. 261 : 1470-1476.

(8) Lee, C.H., S.T. Hu, P.J. Swiatek, S.L. Moseley, S.D. Allen, and M. So. 1985. Isolation of a novel transposon which carries the Escherichia coli enterotoxin STII gene. J. Bacteriol. 162: 615620 .

(9) Levine, M.M., J.B. Kaper, E.B. Black, and M.L. Clements. 1983. New knowledge on patho- 
genesis of bacterial enteric infections as applied to vaccine development. Microbiol. Rev. 47: 510-550.

(10) Miwatani, T., and Y. Takeda. 1976. Vibrio parahaemolyticus-a causative bacterium of food poisoning, Saikon Publishing Co., Ltd., Tokyo.

(11) O'Brien, A.D., and R.K. Holmes. 1987. Shiga and Shiga-like toxins. Microbiol. Rev. 51: 206220.

(12) Pai, C.H., and V. Mors. 1978. Production of enterotoxin by Yersinia enterocolitica. Infect. Immun. 19: 908-911.

(13) Robertson D.C., J.L. McDonel, and R. Dorner. 1985. Escherichia coli heat-labile enterotoxin. Pharmacol. Ther. 28: 303-339.

(14) Sugiyama, H. 1980. Clostridium botulinum neurotoxin. Microbiol. Rev. 44: 419-448.

(15) Yoh, M., T. Honda, and T. Miwatani. 1986. Purification and partial characterization of a Vibrio hollisae hemolysin that relates to the thermostable direct hemolysin of Vibrio parahaemolytics. Can. J. Microbiol. 32: 632-636.

(16) Yoshimura, S., T. Takao, Y. Shimonishi, M. Arita, T. Takeda, H. Imaishi, T. Honda, and T. Miwatani. 1986. A heat-stable enterotoxin of Vibrio cholerae non-Ol: chemical synthesis, and biological and physicochemical properties. Biopolymers 25: S69-S83. 